\title{
PARADIGMA BARU PENINGKATAN MUTU SATUAN PENDIDIKAN DALAM PERSPEKTIF TOTAL QUALITY MANAGEMENT
}

\author{
Oleh: Mursalim*
}

\begin{abstract}
The performance of educational institution as one of public service sector is always the object of criticism by the community who wish a significant change to achieve, at least, the minimum standard. The standard of educational service may function as a guide in planning, actuating and controlling education in terms of actualizing qualified national education. In this case, an operational concept and policy for improving the quality of services through different approach and methods are badly needed. The concept of TQM originally practised in industry would be an alternative to improve the quality of education both at the national and local level.
\end{abstract}

KEYWORDS: Lembaga pendidikan, pelayanan pendidikan, TQM

FAKTA-FAKTA dari berbagai sumber media cetak dan elektronik menunjukkan bahwa masih banyak keluhan masyarakat tentang rendahnya mutu pelayanan publik saat ini. ${ }^{1}$ Masyarakat menilai kinerja pelayanan lembaga milik pemerintah tidak bekerja secara maksimal dan terkesan apa adanya. Pendidikan sebagai salah satu sektor pelayanan publik pemerintah, tidak luput dari berbagai kritikan masyarakat yang menginginkan perubahan bersifat signifikan dan mendesak. Janji pemerintah terhadap setiap warga negara untuk memperoleh pendidikan yang bermutu belum terbukti. ${ }^{2}$ Sebagai jawaban atas tantangan ini, pemerintah telah mengeluarkan berbagai peraturan yang menyangkut Standar Pelayanan Minimal (SPM). SPM bidang pendidikan adalah tolak ukur kinerja pelayanan pendidikan yang diselenggarakan daerah untuk menjamin kualitas pelayanan sektor pendidikan kepada masyarakat dan berfungsi sebagai pedoman dalam perencanaan, pelaksanaan, dan pengawasan pendidikan dalam rangka mewujudkan pendidikan nasional yang bermutu. ${ }^{3}$

Implikasi pada institusi pendidikan baik pusat maupun daerah sebagai organisasi penyelenggara pada sektor pendidikan sebagaimana ter-

${ }^{*}$ Kandidat doktor dalam bidang Manajemen Pendidikan pada Program Pascasarjana Universitas Negeri Jakarta ini adalah dosen Kopertis pada STMIK Catur Sakti. Ia adalah Master of Information Technology (M.Inf.Tech.) dari School of Information Technology, James Cook University of North Queensland, Townsville Australia, 2004. 
tuang dalam peraturan tersebut di atas, memiliki fungsi ganda. Fungsifungsi tersebut dimaksudkan untuk memenuhi tujuan internal kelembagaan dan fungsi sosial memberikan pelayanan maksimal kepada seluruh stakeholder pengguna dalam rangka ikut serta mencerdaskan kehidupan bangsa. ${ }^{4}$ Untuk menjamin keterlaksanaan fungsi-fungsi di atas, maka diperlukan suatu konsep dan kebijakan operasional peningkatan kualitas penyelenggaraan pelayanan jasa pendidikan melalui berbagai pendekatan dan metode manajerial. Pada tataran implementasi tentang konsep mutu, bahwa setiap satuan pendidikan pada jalur formal dan nonformal wajib melakukan penjaminan mutu pendidikan. ${ }^{5}$ Oleh karena itu, manajemen kualitas kelembagaan pendidikan pada hakekatnya bertujuan mengintegrasikan semua fungsi organisasi yang berfokus pada pemenuhan keinginan stakeholder dan tujuan penyelenggara pendidikan sesuai tupoksi masing-masing.

Berdasarkan uraian di atas, maka untuk mencapai suatu kondisi manajemen mutu pelayanan pendidikan yang memenuhi SPM, diperlukan konsep penjaminan mutu dengan sejumlah kriteria yang jelas dan terukur. The British Standards Institute melihat kualitas sebagai "quality" as "the totality of features and characteristics of a product or service that bear on its ability to satisfy stated or implied need". 6 It is clear then that "quality" seems to "depend on what is required"7 or "meeting the customer requirements". Penyelenggaraan pelayanan pendidikan dikatakan bermutu atau berkualitas, apabila mampu menetapkan dan mewujudkan visinya melalui pelaksanaan misinya (aspek deduktif) dan mampu memenuhi kebutuhan stakeholders (aspek induktif). Tujuan Penjaminan Mutu adalah memelihara dan meningkatkan mutu pelayanan minimal pendidikan secara berkelanjutan (continuous improvement), yang dijalankan oleh suatu penyelenggara pendidikan secara internal untuk mewujudkan visi dan misinya, serta memenuhi kebutuhan stakeholders melalui penyelenggaraan kegiatan yang bersifat operasional. Pendidikan yang bermutu akan diperoleh pada satuan pendidikan yang bermutu, dan satuan pendidikan yang bermutu akan menghasilkan SDM yang bermutu pula. Salah satu bentuk manajemen yang berhasil dimanfaatkan dalam dunia industri dan bisa diadaptasi dalam dunia pendidikan adalah Total Quality Management (TQM) pada sistem pendidikan nasional.

\section{RUMUSAN MASALAH}

Berdasarkan uraian di atas, standar mutu pendidikan secara nasional sangat dibutuhkan untuk menjadi kriteria minimal tentang sistem pendidikan. ${ }^{8}$ Hal tersebut tertuang dalam delapan Standar Nasional Pendidikan (SNP) yang mencakup (a) standar isi; (b) standar proses; (c) standar 
kompetensi lulusan; (d) standar pendidik dan tenaga kependidikan; (e) standar sarana dan prasarana; (f) standar pengelolaan; (g) standar pembiayaan; dan (h) standar penilaian pendidikan.

Namun, dari kedelapan standar tersebut ternyata tidak seluruh komponen standar berpengaruh signifikan, sebagaimana pernyataan bahwa "When there is a problem, 85\% of the time it is with the system. 15\% of the time it will be with the workers". ${ }^{9}$ Hal tersebut menunjukkan bahwa $85 \%$ dari masalah-masalah mutu terletak pada manajemen (pengelolaan), dan selebihnya disebabkan oleh pekerja. Oleh sebab itu sejak dini manajemen haruslah dilaksanakan seefektif dan seefisien mungkin. ${ }^{10}$ Untuk memudahkan pembahasan pada tulisan ini selanjutnya, maka perumusan masalah adalah sebagai berikut:

a. Bagaimanakah konsep manajemen peningkatan mutu yang dapat diterapkan di tingkat satuan pendidikan?

b. Bagaimana mengaplikasikan konsep peningkatan mutu pada satuan pendidikan?

\section{PEMBAHASAN}

\section{Konsep Manajemen Peningkatan Mutu}

Konsep-konsep peningkatan mutu pada dunia industri telah lama digunakan atau diadaptasi oleh satuan pendidikan. Contoh yang paling simpel adalah penerapan pada beberapa perangkat dan teknik seperti yang sering digunakan dalam analisa bisnis. ${ }^{11}$ Oleh karena itu, satuan pendidikan hendaknya memahami perkembangan manajemen sistem industri modern agar mampu mendesain, menerapkan, mengendalikan, dan meningkatkan kinerja sistem pendidikan yang memenuhi kebutuhan manajemen sistem industri modern. Hal tersebut dikemukakan oleh Susan bahwa "Schools must adopt a TQM approach that continually looks to improve the effective use of resources, maximize the opportunities for pupils, develop their staff and fulfil the needs of the community".12 Pernyataan tersebut mengharuskan satuan pendidikan mengadopsi pendekatan TQM yang secara terus-menerus berusaha untuk meningkatkan efektivitas penggunaan sumberdaya, memaksimalkan kesempatan bagi setiap orang, mengembangkan kebutuhan staf, dan memenuhi kebutuhan masyarakat.

Usaha tersebut dapat dilakukan melalui continuous reassessment untuk meningkatkan efektivitas. Satuan pendidikan hendaknya mereviu sistem organisasi agar usaha peningkatan mutu dapat berlangsung tanpa harus meningkatkan beban kerja. Schools can do this by continuous reassessment to improve effectiveness with less effort. They need to review the school's organization 
so that new development can be taken on without increasing workload. Penetapan tujuan satuan pendidikan perlu dilakukan dan secara reguler melakukan evaluasi terhadap pencapaian tujuan sebagai dasar perencanaan selanjutnya. Untuk mencapai hasil yang maksimal maka satuan pendidikan hendaknya meningkatkan kualitas kepemimpinan yang efektif pada semua jenjang. Hal tersebut dapat diwujudkan dengan membangun komunikasi yang efektif sebagaimana pernyataan Susan sebagai berikut; "Effective communication and staff involvement in decision making are of paramount importance and this needs to be developed by a school. By adopting these strategies the school will be provided with a systematic way of guaranteeing that all activities happen as planned".13 Komunikasi yang efektif dengan melibatkan staf dalam pengambilan keputusan merupakan suatu hal yang sangat penting. Dengan mengadopsi strategi tersebut, maka satuan pendidikan memiliki arah yang sistematis dalam menjamin seluruh aktivitas berjalan sesuai dengan yang direncanakan. ${ }^{14}$

Satuan pendidikan yang menggunakan pendekatan TQM dalam menjalankan pelayanan jasa berusaha semaksimal mungkin meningkatkan daya saing organisasi melalui perbaikan terus menerus atas produk, jasa pendidikan, pendidik dan tenaga kependidikan, proses belajar mengajar, dan beradaptasi dengan lingkungan masyarakatnya. Untuk menunjang pencapaian usaha tersebut satuan pendidikan dapat mengadopsi sepuluh unsur utama TQM. Kesepuluh unsur tersebut adalah; fokus pada pelanggan (internal dan eksternal); obsesi terhadap kualitas; menggunakan pendekatan ilmiah; komitmen terhadap tujuan jangka panjang; membangun kerjasama tim; perbaikan kualitas secara berkesinambungan; pendidikan dan latihan; kebebasan terkendali; kesatuan visi, misi dan tujuan; dan ketertiban serta pemberdayaan seluruh stakeholder pendidikan. ${ }^{15}$

Unsur utama TQM di atas melahirkan empat prinsip perbaikan kualitas meliputi: kepuasan pelanggan, respek terhadap setiap orang, manajemen berdasarkan fakta, dan perbaikan berkesinambungan. Dalam konteks perbaikan mutu satuan pendidikan, maka proses penerapan prinsip tersebut harus dipandang sebagai suatu peningkatan terus-menerus (continuous process improvement), yang dimulai dari sederet siklus sejak adanya ide-ide untuk menghasilkan suatu produk, pengembangan produk, proses produksi, sampai distribusi kepada konsumen. Seterusnya, berdasarkan informasi sebagai umpan balik yang dikumpulkan dari pengguna produk (pelanggan) itu dapat dikembangkan ide-ide kreatif untuk menciptakan produk baru atau memperbaiki produk lama beserta proses produksi yang ada saat ini. ${ }^{16}$

Satuan pendidikan yang menerapkan TQM diharapkan mampu menjaga efisiensi, produktivitas dalam bentuk layanan jasa, berorientasi 
pada kesuksesan jangka panjang, dan mengadopsi semua kontribusi individu dalam rangka perbaikan berkelanjutan (TQM is about efficiency, productivity, long-term success and adopting an attitude that all individuals can contribute to the pursuit of continuous improvement). ${ }^{17}$ Lebih lanjut Susan mengatakan bahwa "Whatever the institution, achieving total quality is an attitude of mind. It is about driving out fear, breaking down barriers. It is about encouraging people to educate and develop themselves to work in teams, to think for themselves and believe that things can be continually improved. More than anything else the improvement of quality is as much about the way people work together as it is about what they actually do. Everyone needs to believe in quality and contribute towards it by constantly improving their standards". 18

Dalam menggerakkan segala kemampuan satuan pendidikan untuk mencapai mutu yang ditetapkan, harus dikembangkan adanya kerjasama antar unsur-unsur pelaku proses mencapai hasil mutu. Janganlah diantara mereka terjadi persaingan yang mengganggu proses mencapai hasil mutu tersebut. Mereka adalah satu kesatuan yang harus bekerjasama dan tidak dapat dipisahkan satu sama lain untuk menghasilkan mutu sesuai yang diharapkan. Selain itu, perlu adanya upaya menghasilkan budaya satuan pendidikan yang kondusif bagi perbaikan berkelanjutan dimana setiap orang dapat berpartisipasi. Jaminan kualitas juga perlu diintegrasikan ke dalam semua proses dan fungsi lembaga pendidikan. Semua itu memerlukan perubahan perilaku orang-orang, sikap mental dan praktek pekerjaan dalam berbagai cara. Merubah perilaku dan sikap mental orang adalah salah satu tugas manajemen yang paling sulit, memerlukan kekuatan besar dan keterampilan persuatif dan memotivasi.

\section{Aplikasi TQM pada Satuan Pendidikan}

Manajemen peningkatan mutu satuan pendidikan adalah suatu metode peningkatan mutu yang bertumpu pada satuan pendidikan itu sendiri, mengaplikasikan sekumpulan teknik, mendasarkan pada ketersediaan data kuantitatif \& kualitatif, dan pemberdayaan semua komponen satuan pendidikan untuk secara berkesinambungan meningkatkan kapasitas dan kemampuan organisasi satuan pendidikan guna memenuhi kebutuhan peserta didik dan masyarakat. Aplikasi Total Quality Management (TQM) dalam konsep pendidikan berfungsi sebagai "a philoshophy improvement which can provide any educational institution with a set of practical tools for meeting and exceeding present and future coctumer need, wants and expextations". ${ }^{19}$ Pernyataan tersebut mengandung dua konsep utama, yaitu; perbaikan terus menerus (continous improvement), dan kedua berhubungan dengan alat-alat dan teknik seperti "brainstorming" dan "force field analysis" 
(analisis kekuatan lapangan), yang digunakan untuk perbaikan kualitas dalam tindakan manajemen untuk mencapai kebutuhan dan harapan pelanggan. Sedangkan, "Total Quality Management is about creating a quality culture where the aim of every member of staff is to delight their customer, and where the stucture of their organizations allow to do so, ${ }^{20}$ berhubungan dengan penciptaan budaya kualitas oleh pendidik dan tenaga kependidikan untuk menyenangkan konsumen dengan dukungan organisasi. Untuk itu, maka perlu perbaikan program satuan pendidikan secara lebih kreatif dan konstruktif serta peningkatan kualitas program yang dapat mengubah kultur satuan pendidikan. Franklin P. Schargel menegaskan bahwa "Total Quality Educations is a process which involves focussing on meeting and exceeding customer expectations, continuous improvement, sharing responsibilities with employees, and reducing scrap and rework" bahwa mutu terpadu pendidikan dipahami sebagai suatu proses yang melibatkan pemusatan pada pencapaian kepuasan harapan pelanggan pendidikan, perbaikan terus-menerus, pembagian tanggung jawab dengan para pegawai, dan pengurangan pekerjaan tersisa dan pengerjaan kembali.

Peningkatan kualitas sistem pelayanan jasa pendidikan secara berkelanjutan, terus-menerus, dan terpadu merupakan tujuan TQM.21 Pencapaian tujuan tersebut dapat di wujudkan dengan menggunakan prinsipprinsip berupa; pemokusan pada pelanggan satuan pendidikan, peningkatan kualitas proses, dan melibatkan semua komponen lembaga melalui metode PDCA (Plan-Do-Chek-Act). Metode ini pertama kali dikembangkan oleh Sheward dan divisualisasikan oleh Deming, berupa siklus PDCA.

Berangkat dari siklus di atas bisa diambil pengertian dengan beberapa tahapan, yaitu: (1) Plan berisi penentuan proses yang mana yang perlu diperbaiki, menentukan perbaikan apa yang dipilih, dan menentukan data dan informasi yang diperlukan untuk perbaikan proses; (2) Do, beirisi pengumpulan data dasar tentang jalannya proses, implementasi perubahan yang dikehendaki (skala kecil), mengumpulkan data untuk mengetahui perubahan (ada perbaikan atau tidak); (3) Check, berisi langkah pemimpin untuk menafsirkan hasil implementasi (berhasil atau tidak) atau upaya pemimpin untuk memperoleh pengetahuan baru tentang proses yang berada dalam tanggung jawabnya; (4) Act, berupa pengambilan keputusan perubahan mana yang akan diimplementasikan, penyusunan prosedur baku, pelatihan ulang bagi anggota terkait, dan pemantauan secara kontinu.

Mekanisme pencapaian mutu tentunya membutuhkan perencanaan yang matang, karena total quality adalah sesuatu yang diraih dengan ber- 
kelanjutan. Hal tersebut dikemukakan oleh Susan sebagai berikut; “They need to set and implement educational objectives for the school and review these regularly alongside achievements, as a basis for future planning. Schools need to show tact and care over schemes for staff development and appraisal, developing quality leadership at all levels".22 Oleh karena itu, dalam rangka mencapai target mutu, maka kesalahan harus dieliminasi untuk mencapai keunggulan kompetitif alumninya dan keunggulan kooperatif dengan lulusan yang lain sesuai dinamika dunia kerja.

Total Quality Management dalam pendidikan yang didefinisikan sebagai "a degree of excellence", "fitness for purpose or use", "zero defect",23 "conformance to requirements", 24 while Deming 25 stressed that "Quality should be aimed at the needs of the customer, present and future". Oleh karena itu mempelajari dan memahami Total Quality Management secara menyeluruh mutlak diperlukan guna mengadopsi jiwa dan filosofi untuk perbaikan terus-menerus (continous improvement). Langkah selanjutnya adalah menetapkan quality assurance (QA) dan quality control (QC) untuk menilai jaminan kualitas saat ini dan program pengendalian mutu. Kedua aspek tersebut penting untuk membangun sistem kualitas terpadu.

Langkah berikutnya adalah mempersiapkan orang-orang untuk perubahan, menilai budaya mutu sebagai tujuan untuk mempersiapkan perbaikan, melatih orang-orang untuk bekerja pada suatu kelompok. Selain itu, perlu juga mempelajari teknik untuk menyerang atau mengatasi akar persoalan (penyebab) dan mengaplikasikan tindakan koreksi dengan menggunakan teknik dan alat Total Quality Management. Sebagai langkah implementasi diperlukan pemilihan dan penetapan pilot project untuk diaplikasikan dan menetapkan prosedur tindakan perbaikan dan sadari akan keberhasilannya. Sementara, untuk mempertahankan kualitas yang sudah diraih perlu menciptakan komitmen dan strategi yang benar mutu terpadu oleh pemimpin yang akan menggunakannya. Hal tersebut dimaksudkan untuk memelihara jiwa mutu terpadu dalam penyelidikan dan aplikasi pengetahuan yang amat luas.

Satuan pendidikan, harus memenuhi beberapa syarat untuk dapat mengimplementasikan TQM. Syarat pertama yaitu peningkatan kualitas secara berkesinambungan. Sebagai suatu pendekatan TQM mencari suatu bentuk permanen dalam lembaga, sehingga fokus bukan diarahkan jangka pendek, melainkan diarahkan pada peningkatan kualitas jangka panjang. Inovasi konstan, peningkatan dan perubahan merupakan inti TQM, dan lembaga-lembaga tersebut dalam pelaksanaan peningkatan secara berlanjut. Hal tersebut sesuai dengan pernyataan "this is true in education where "quality" will change with time, reflecting society's interpretation of educational 
needs and "the intensity of its moral and financial commitment to fulfilling them". ${ }^{26}$

Perubahan budaya organisasi merupakan syarat ke dua yang harus dilakukan dalam rangka mengarahkan budaya kualitas yang baru. Budaya satuan pendidikan dapat menjadi instrumen keunggulan kompetitif yang utama apabila budaya lembaga pendidikan mendukung strategi lembaga pendidikan, dalam hal ini implementasi TQM, dan bila budaya lembaga pendidikan dapat menjawab atau mengatasi tantangan lingkungan dengan cepat dan tepat dan pada akhirnya budaya lembaga pendidikan akan berpengaruh terhadap kinerja lembaga pendidikan. Adanya keterkaitan hubungan antara budaya korporat dengan kinerja lembaga pendidikan dapat dijelaskan dalam model diagnosis budaya lembaga pendidikan Tiernay, bahwa semakin baik kualitas faktor-faktor yang terdapat dalam budaya lembaga pendidikan makin baik pula kinerja lembaga pendidikan tersebut. ${ }^{27}$

Dalam melaksanakan komunikasi organisasi harus dilakukan seefektif mungkin agar pesan yang disampaikan dapat dilaksanakan sesuai dengan tujuan. Komunikasi pesan lebih bersifat rangsangan terhadap tindakan mental daripada sekedar penyesuaian secara fisik, sebagaimana kutipan berikut:; "the difference between an adjustment to a physical stimulus and a mental act is that the latter involves response to a thing in its meaning; the former does not". ${ }^{28}$ Adanya suatu komunikasi yang efektif, baik secara internal maupun secara eksternal, antara pelanggan dan suplier. Semua jaringan dan media komunikasi baik secara vertikal maupun horizontal perlu dioptimalkan. Hal ini sangat diperlukan untuk membentuk iklim kondusif bagi terciptanya budaya kualitas yang diharapkan.

Satuan pendidikan yang unggul akan selalu menjaga kedekatan dengan pelanggan serta memiliki obsesi terhadap kualitas. Pemimpin satuan pendidikan harus mengutamakan dan memuaskan pelanggan. Hal ini didasarkan pada ciri utama penentu kualitas versi TQM bahwa pelangganlah yang akhirnya menentukan kualitas. Sedangkan, fokus pada pelanggan dibagi menjadi dua kategori, yaitu; pelanggan internal dan external. Fokus TQM terhadap pelanggan bukan sekedar memenuhi kebutuhan dari luar, akan tetapi kolega-koleganya yang ada dalam lembaga juga merupakan pelanggan. Keseimbangan dalam memenuhi semua pelanggan baik internal maupun eksternal harus dilakukan secara proporsional.

Syarat berikutnya adalah pemasaran internal yaitu alat untuk mengkomunikasikan berbagai informasi pada staf guna meyakinkan mereka tentang apa yang terjadi di satuan pendidikan, sehingga staf memiliki 
kesempatan untuk memberikan ide umpan balik. Pemasaran internal adalah salah satu bentuk mengkomunikasikan ide kepada lingkungan internal. Jika pemasaran internal berjalan dengan baik, niscaya dukungan terhadap implementasi TQM dalam bidang pendidikan dapat berjalan dengan baik pula, justru melalui pemasaran internal itulah nantinya menjadi pendongkrak pada pemasaran eksternal yang lebih luas.

Menunjukkan kepedulian pada standar akademik yang memadai merupakan syarat mutlak bagi sebuah satuan pendidikan. Mempersatukan unsur terbaik bagi profesionalisme dengan total quality merupakan modal penting untuk meraih sukses. Fokuskan keprofesionalannya kepada keinginan dan kepuasan pelanggan dalam jangka panjang. Implikasinya, opini pelanggan terhadap sistem layanan jasa di satuan pendidikan menjadi terbentuk dengan baik. Hal tersebut tercermin dalam pernyataan berikut ini; "Since morality is concerned with conduct, any dualisms which are set up between mind and activity must reflect themselves in the theory of morals. Since the formulations of the separation in the philosophic theory of morals are used to justify and idealize the practices employed in moral training, a brief critical discussion is in place" ${ }^{29}$

Dalam menerapkan TQM harus mengantisipasi gaya belajar siswa secara serius, sehingga mendapatkan strategi yang baik untuk melayani masing-masing individu yang memiliki perbedaan dalam belajar. John Dewey percaya bahwa "learning was active and schooling unnecessarily long and restrictive. His idea was that children came to school to do things and live in a community which gave them real, guided experiences which fostered their capacity to contribute to society". ${ }^{30}$ Penggunaan TQM dalam kelas pertama harus menetapkan misi yang disepakati antar siswa dan guru. Berdasarkan hasil kesepakatan tersebut timbul keinginan untuk mencapai misi tersebut. Dalam proses menentukan kesepakatan bersama diperlukan adanya ketetapan tentang kualitas dari forum agar dapat diberikan umpan balik serta memberikan kesempatan kepada siswa mengatur cara belajar tersendiri. Selain itu wakil dari orang tua juga diperlukan untuk terlibat dalam kesepakatan, hal ini untuk mengantisipasi kesalahan dan mencari jalan keluar.

Syarat terakhir dalam implementasi TQM di satuan pendidikan adalah identifikasi dan penanggulangan hambatan. Ada beberapa hambatan yang sering timbul dalam pelaksanaan TQM di satuan pendidikan, antara lain; (1) pemimpin membutuhkan hasil dari TQM, di pihak lain mereka enggan memberikan dukungan; (2) staf tidak memahami tujuan dan misi lembaga; (3) peran staf madya, yang memiliki peran sangat penting karena mereka bertanggung jawab atas operasional lembaga 
sehari-hari dan berperan juga sebagai saluran komunikasi yang utama. Staf madya tidak boleh bertindak sebagai inovator kecuali staf senior sudah mengemukakan misinya di masa yang akan datang. Staf senior harus konsisten dalam menasehati dan menyampaikan pesan-pesan untuk meningkatkan kualitas.

\section{PENUTUP}

Berdasarkan uraian di atas, maka dapat disimpulkan sebagai berikut:

1. Pemerintah perlu memperbaiki mutu pelayanan jasa pendidikan secara nasional. Dalam perbaikan mutu pendidikan tersebut manajemen mutu yang diadaptasi dari Total Quality Management yang ada pada Industri Modern, layak untuk diadaptasi dalam Manajemen Pendidikan. Pada prinsipnya manajemen mutu ini berbasis satuan pendidikan memberdayakan semua komponen, dan satuan pendidikan sebagai unit produksi yang melayani siswa, orang tua, pihak pemakai/ penerima lulusan, dan guru/staf.

2. Pencapaian tujuan tersebut dapat diwujudkan dengan menggunakan prinsip-prinsip berupa; pemokusan pada pelanggan satuan pendidikan, peningkatan kualitas proses, dan melibatkan semua komponen lembaga melalui metode PDCA (Plan-Do-Chek-Act). Metode ini pertama kali dikembangkan oleh Sheward dan divisualisasikan oleh Deming, berupa siklus PDCA.

3. Masalah yang dihadapi dalam pelaksanaan manajemen peningkatan mutu adalah sikap mental para pengelola pendidikan, tidak adanya tindak lanjut dari evaluasi program, gaya kepemimpinan yang tidak mendukung, kurangnya rasa memiliki para pelaksana pendidikan dan belum membudayanya prinsip melakukan sesuatu secara benar dari awal. Kendala-kendala itu disebabkan oleh adanya kepemimpinan yang tidak berjiwa entrepeneur dan tidak tangguh, adanya sentralistrik manajemen pendidikan, dan rendahnya etos kerja aparat pengelola, kurangnya melibatkan semua pihak untuk berpartisipasi.

4. Penggunaan TQM dalam kelas pertama harus menetapkan misi yang disepakati antar siswa dan guru. Berdasarkan hasil kesepakatan tersebut timbul keinginan untuk mencapai misi tersebut. Dalam proses menentukan kesepakatan bersama diperlukan adanya ketetapan tentang kualitas dari forum agar dapat diberikan umpan balik serta memberikan kesempatan kepada siswa mengatur cara belajar tersendiri. Selain itu wakil dari orang tua juga diperlukan untuk mengatisipasi kesalahan dan mencari jalan keluar. 
5. Perlu ditingkatkan etos kerja, motivasi, kerjasama tim, moral kerja yang baik, punya rasa memiliki, mau bekerja keras agar Manajemen Mutu Pendidikan dapat terlaksana secara optimal sehingga mampu menghasilkan Mutu SDM. Disamping itu diperlukan seorang kepala satuan pendidikan yang berjiwa pemimpin dengan visi yang baik.

6. Bagaimanapun baiknya konsep TQM, memang tidak menjamin sepenuhnya bahwa TQM bisa berhasil diimplimentasikan pada satuan pendidikan. Hal ini menunjukkan bahwa konsep TQM masih perlu direvitalisasi. Oleh karena itu, diperlukan pengembangan inovasi-inovasi dan konsep sehingga benar-benar sesuai dengan karakteristik satuan pendidikan yang bersangkutan. Selain itu, kiranya perlu adanya sikap ketelatenan dan kesabaran serta proaktif semua pihak untuk selalu ditingkatkan serta diupayakan perbaikan secara terus menerus untuk optimalisasi keberhasilan

\section{CATATAN AKHIR}

1. Hasil kompilasi penulis dari fakta-fakta yang termuat dalam berbagai sumber media cetak dan elektronik (koran, televisi, hasil penelitian, majalah, dll.)

2. Undang-Undang Sisdiknas Tahun 2003 Bab V Pasal 5 Ayat 1.

3. Surat Keputusan Menteri Pendidikan Nasional Nomor 129a/U/2004 tentang Standar Pelayanan Minimal Bidang Pendidikan.

4. Ibid., h. 1.

5. Peraturan Pemerintah Nomor 19 tahun 2005 Bab VI Pasal 5 Ayat 1.

6. British Standards Institution, Quality Systems, BS EN ISO 9002, BSI, London, 1994.

7. J.S. Oakland, Total Quality Management, Butterworth-Heinemann, Oxford, 1989, h. 20.

8. Ibid.h. 1.

9. TQM in Education, The Theory and How To Put It to Work Myron Tribus, Exergy, Inc. Hayward, CA, h. 21.

10. M. Juran, Management Breakthrough, A New Concept of the Manager's Job, McGraw-Hill, New York, NY, 1964, h. 96.

11. Garbutt Susan, Education and Training, Volume 38 Number 7, pp. 16-22 @ MCB University Press ISSN 0040-0912, 1996, h. 2.

12. Ibid, h. 3.

13. Ibid, h. 4.

14. Terjemahan bebas penulis dari naskah aslinya.

15. Vincent Gaspersz, Penerapan Total Management In Education (TQME) Pada Perguruan Tinggi di Indonesia, Jurnal Pendidikan (online), Jilid 6, No. 3, 2000, (http://www.ut.ac.id diakses 25 Februari 2010).

16. Ibid, h. 5

17. Op. cit. h. 4 
18. Garbutt Susan, op.cit., h. 6.

19. Edward Sallis, Total Quality Management in Education, London, Kogan Page Educational Management Series, 1993, h. 67.

20. Edward Sallis, ibid., h. 68.

21. Tunner \& Detoro, Total Quality Manajement: Tree Steeps to Continuous Improvement, Massachuset, Addison-Weley Publishing Company, 1992, h. 56.

22. Garbutt Susan, op.cit., h. 8.

23. M. Juran, op.cit., h. 97.

24. P. Crosby, Quality Is Free, McGraw-Hill, New York, NY, 1979, h. 45.

25. W.E. Deming, Out of the Crisis: Quality Productivity and Competitive Position, Cambridge University Press, Cambridge, 1986, h. 76.

26. P. Mortimore and C. Stone, "Measuring educational quality", British Journal of Education Studies, 1990, h. 69.

27. D. Moeljono, Budaya Korporat dan Keunggulan Korporasi, PT. Elex Media Komputindo, Jakarta, 2003, h. 42.

28. J. Dewey, Democracy and Education. An introduction to the philosophy of education (1966 edn.), New York: Free Press, 1916, h. 32.

29. Ibid h. 12.

30. Ibid, h. 14.

\section{DAFTAR PUSTAKA}

British Standards Institution, Quality Systems, BS EN ISO 9002, BSI, London, 1994.

Crosby, P., Quality Is Free, McGraw-Hill, New York, NY, 1979.

Deming, W.E., Out of the Crisis: Quality Productivity and Competitive Position, Cambridge University Press, Cambridge, 1986.

Dewey, J., Democracy and Education. An introduction to the philosophy of education (1966 edn.), New York: Free Press, 1916.

Gaspersz, Vincent, Penerapan Total Management In Education (TQME) Pada Perguruan Tinggi di Indonesia, Jurnal Pendidikan (online), Jilid 6, No. 3, 2000, (http://www.ut.ac.id).

Juran, M., Management Breakthrough, A New Concept of the Manager's Job, McGrawHill, New York, NY, 1964.

Moeljono, D., Budaya Korporat dan Keunggulan Korporasi, PT. Elex Media Komputindo, Jakarta, 2003.

Mortimore, P. and Stone, C., "Measuring educational quality", British Journal of Education Studies, 1990.

Oakland, J.S., Total Quality Management, Butterworth-Heinemann, Oxford, 1989.

Peraturan Pemerintah Nomor 19 tahun 2005 Bab VI Pasal 5 Ayat 1.

Sallis, Edward, Total Quality Management in Education, London, Kogan Page Educational Management Series, 1993.

Surat Keputusan Menteri Pendidikan Nasional Nomor 129a/U/2004 tentang Standar Pelayanan Minimal Bidang Pendidikan.

Susan, Garbutt, Education and Training, Volume 38, Number 7, pp. 16-22 @ MCB University Press ISSN 0040-0912, 1996. 
TQM in Education, The Theory and How To Put It to Work Myron Tribus, Exergy, Inc.Hayward, CA.

Tunner \& Detoro, Total Quality Manajement: Tree Steeps to Continuous Improvement, Massachuset, Addison-Weley Publishing Company, 1992.

Undang-Undang Sisdiknas Tahun 2003 Bab V Pasal 5 Ayat 1. 